\title{
An Unusual Presentation of Celiac Disease: Recurrent Spontaneous Abortus
}

\author{
Çölyak Hastalığının Nadir Bir Prezentasyonu: Rekürren Spontan Abortus
}

\author{
(1) Ahmet Yozgat ${ }^{1}$, (1) Kadir Serkan Yalçın² \\ 'Division of Gastroenterology, Department of Internal Medicine, Ufuk University Faculty of Medicine, Ankara, Turkey \\ ${ }^{2}$ Department of Internal Medicine, Lokman Hekim University Faculty of Medicine, Ankara, Turkey
}

\begin{abstract}
Celiac disease is an autoimmune, inflammatory disease that may affect many systems and organs. Herein we will report a young patient diagnosed with celiac disease after three times of spontaneous abortus. Clinicians should be aware that celiac disease may have some diverse clinical presentations which should be kept in mind during the differential diagnosis of patients with recurrent abortus.

Keywords: Celiac Disease; Gluten Free Diet; Spontaneous Abortus
\end{abstract}

Cesia eliac disease is an autoimmune, inflammatory disease that may affect many systems and organs. Although the most common symptoms in celiac disease are the gastrointestinal symptoms; the disease may also be presented with the extra-intestinal symptoms. ${ }^{[1]}$ If undiagnosed, severe complications such as malnutrition, vitamin deficiencies, and osteoporosis may take place in the course of the disease which would be preventable with a gluten free diet. Herein, we will report a patient diagnosed with celiac disease after three spontaneous abortus, which may have many diverse clinical presentations that may make the diagnosis difficult.

\section{Case Report}

A 28-year old female patient was admitted to the gastroenterology department with mild, non-specific dyspeptic symptoms. Her medical history revealed that she was under a follow-up by the obstetrics and gynecology department due to spontaneous abortions. In the last 3 years, she had three spontaneous abortions in between $9^{\text {th }}-11^{\text {th }}$ gestational weeks. She was having regular menstrual cycles and the last abortus was about 6 months ago. The only medication she was taking was folic acid. Her laboratory evaluations revealed normal blood count, liver and renal functions, and blood glucose and thyroid function tests. Her family history revealed that her younger sister was diagnosed with celiac disease about 3 years ago while she was evaluated for chronic diarrhea. Her serological tests (tissue transglutaminase $\lg A$ and $\lg G$ and anti-endomysial $\lg A$ and $\lg G$ ) were obtained to rule out the celiac disease and they were highly positive. Upper gastrointestinal en-

Cite this article as: Yozgat A, Yalcin KS. An Unusual Presentation of Celiac Disease: Recurrent Spontaneous Abortus. Lokman Hekim Health Sci 2021;1(1):34-35.

Correspondence: Ahmet Yozgat, M.D. Ufuk Universitesi Tip Fakultesi, Ic Hastaliklari Anabilim Dali, Gastroenteroloji Bilim Dali, Ankara, Turkey

E-mail: a_yozgat@yahoo.com Submitted: 18.07.2021 Accepted: 29.07.2021

Copyright 2021 Lokman Hekim Health Sciences

OPEN ACCESS This is an open access article under the CC BY-NC license (http://creativecommons.org/licenses/by-nc/4.0/). 
doscopy was performed which revealed highly edematous changes in proximal duodenum. Biopsy revealed lymphocytic infiltration of the duodenal mucosa with marked villous atrophy (Marsh 3b). The patient was diagnosed with celiac disease and a gluten- free diet was started. She gave a healthy birth during the $18^{\text {th }}$ month of a gluten- free diet.

\section{Discussion}

Although the most common symptoms in celiac disease are the gastrointestinal symptoms, the disease may also be presented with the extra-intestinal symptoms; and in undiagnosed or untreated cases, severe systemic complications may take place. Obstetric complications such as miscarriage and preterm labor associated with celiac disease have been reported before. ${ }^{[1,2]}$ In that association, antitransglutaminase antibodies were accused that were causing impaired apoptosis of syncytiotrophoblasts and disturbed endometrial receptivity which was in turn resulting in implantation and placentation disorder. ${ }^{[3]}$ However, recently, Sarikaya et al did not determine any association between antitransglutaminase antibodies and unexplained recurrent pregnancy losses. ${ }^{[4]}$ In our case, while investigating for mild elevations in liver function tests, the patient was diagnosed with celiac disease and responded well to the gluten free diet and gave a healthy birth. However, to the best of our knowledge, this is the first case reported in literature, presented with miscarriage, and diagnosed with celiac disease.

In conclusion, clinicians should be aware that celiac disease may have some diverse clinical presentations which should be kept in mind during the differential diagnosis of patients with recurrent abortus.

Peer-review: Externally peer-reviewed.

Informed Consent: Written informed consent was obtained from patients who participated in this study.

Authorship Contributions: Concept: AY, KSY; Design: AY, KSY; Supervision: AY, KSY; Data Collection or Processing: AY, KSY; Analysis or Interpretation: AY, KSY; Literature Search: AY, KSY; Writing: AY, KSY; Critical Review: AY, KSY.

Conflict of Interest: None declared.

Financial Disclosure: The authors declared that this study received no financial support.

\section{References}

1. Saccone G, Berghella V, Sarno L, Maruotti GM, Cetin I, Greco $L$, et al. Celiac disease and obstetric complications: a systematic review and metaanalysis. Am J Obstet Gynecol 2016;214(2):225-34.

2. Anjum N, Baker PN, Robinson NJ, Aplin JD. Maternal celiac disease autoantibodies bind directly to syncytiotrophoblast and inhibit placental tissue transglutaminase activity. Reprod Biol Endocrinol 2009;7:16.

3. Sarikaya E, Tokmak A, Aksoy RT, Pekcan MK, Alisik M, Alkan A. The association between serological markers of celiac disease and idiopathic recurrent pregnancy loss. Fetal Pediatr Pathol 2017;36(5):373-9.

4. Mohn A, di Ricco L, Magnelli A, Chiarelli F. Celiac disease-associated vertigo and nystagmus. J Pediatr Gastroenterol Nutr 2002;34(3):317-8. 